\title{
Belhassen Syndrome in Teenager Originating from Left Anterior Fascicle
}

Lívia Teixeira Martins e Silva ${ }^{1, *}$, Paula Damasco do Vale ${ }^{2}$, Jairo Macedo da Rocha ${ }^{1,2}$, Carla Septimio Margalho ${ }^{1,2}$, Henrique César de Almeida Maia ${ }^{1,2}$

\section{ORCID IDs}

Silva LTM (D) https://orcid.org/0000-0002-8282-442X

Vale PD (D) https://orcid.org/0000-0003-0244-5524
Rocha JM (D) https://orcid.org/0000-0002-8308-4398

Margalho CS (D) https://orcid.org/0000-0003-4844-7752

Maia HCA (D) https://orcid.org/0000-0001-9215-9585

\begin{abstract}
A 16-year-old female patient was hospitalized due to narrow QRS tachycardia suggestive of fascicular ventricular tachycardia. Initially, the differential diagnosis with supraventricular tachycardia can be challenging. The tachyarrhythmia is well controlled with medication, but electrophysiological study and ablation may be necessary in patients who remain symptomatic.
\end{abstract}

KEYWORDS: Arrhythmia; Ventricular tachycardia; Radiofrequency ablation.

1. Ritmocardio Serviço de Arritmia e Eletrofisiologia de Brasília - Brasília/DF - Brazil.

2. Instituto Hospital de Base do Distrito Federal - Serviço de Eletrofisiologia - Brasília/DF - Brazil.

*Corresponding author: liviatmartins@gmail.com

Received: Sep 16, 2020 | Accepted: Oct 24, 2020 


\section{INTRODUCTION}

Idiopathic fascicular ventricular tachycardia (VT) is uncommon and present in a structurally normal heart. It can originate from any portion of the left ventricular fascicular system, its occurrence being even rarer from the left anterior fascicle. It is more common in young people, showing good response to drug treatment. With the failure of clinical management, there is the possibility of radiofrequency ablation, which has high success rates.

\section{CASE REPORT}

A 16-year-old female adolescent was seen in the emergency room in November 2019 complaining of palpitation, dyspnea, reporting that such symptoms started in childhood. An electrocardiogram of the crisis was performed (Fig. 1), which showed a narrow QRS tachycardia, with right bundle branch block morphology, V5 transition, lower axis, suggestive of VT. After amiodarone administration, tachyarrhythmia was reversed. A transthoracic echocardiogram was performed and showed preserved left ventricular ejection fraction, without enlarged cardiac chambers or segmental changes. Due to refractoriness of palpitation symptom even after the use of propranolol 80 $\mathrm{mg} /$ day and verapamil $240 \mathrm{mg} /$ day, she was referred for electrophysiological study and radiofrequency ablation.

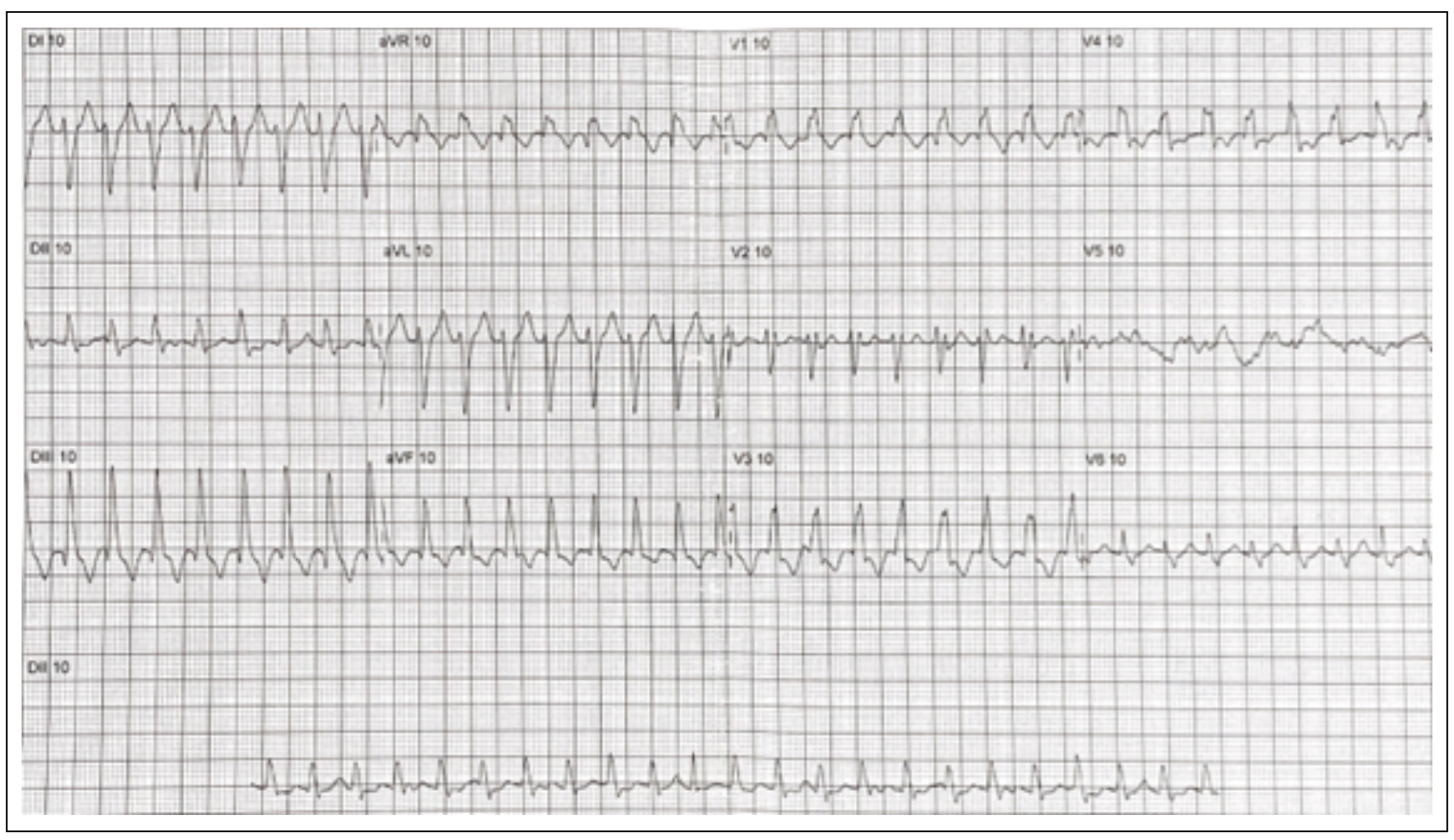

Figure 1. VT electrocardiogram of the left anterior fascicular VT

The procedure was performed under sedation. Decapolar and ablation catheter of $4 \mathrm{~mm}$ were introduced through two punctures in the right femoral vein, under fluoroscopy, for electrophysiological study, electroanatomical mapping using EnSite and VT activation map. Tachyarrhythmia was induced through programmed ventricular stimulation, with no precocity in the right ventricle. Thus, a puncture of the right femoral artery was performed for retroaortic access of the left ventricle. In sinus rhythm, Purkinje potential was identified, preceding the QRS complex (Fig. 2) by $20 \mathrm{~ms}$. 


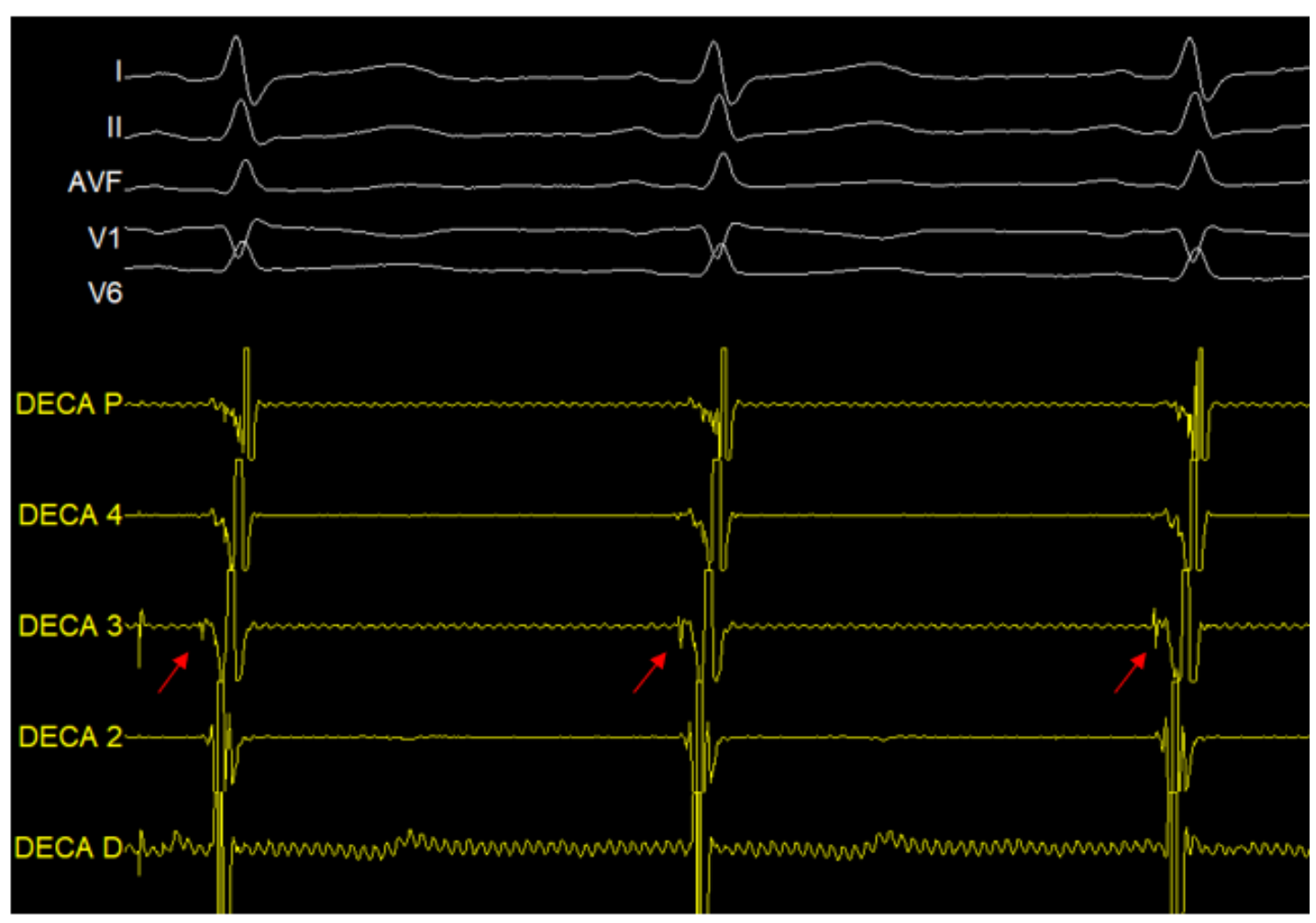

Figure 2. Intracavitary electrogram showing Purkinje potential during sinus rhythm.

The VT activation map (Fig. 3) showed earlier Purkinje potential (15 ms) in the left ventricular anterior fascicle region (Fig. 4). Radiofrequency pulses were applied there, with interruption of the arrhythmia. Ventricular stimulation protocols were not able to induce tachyarrhythmia.

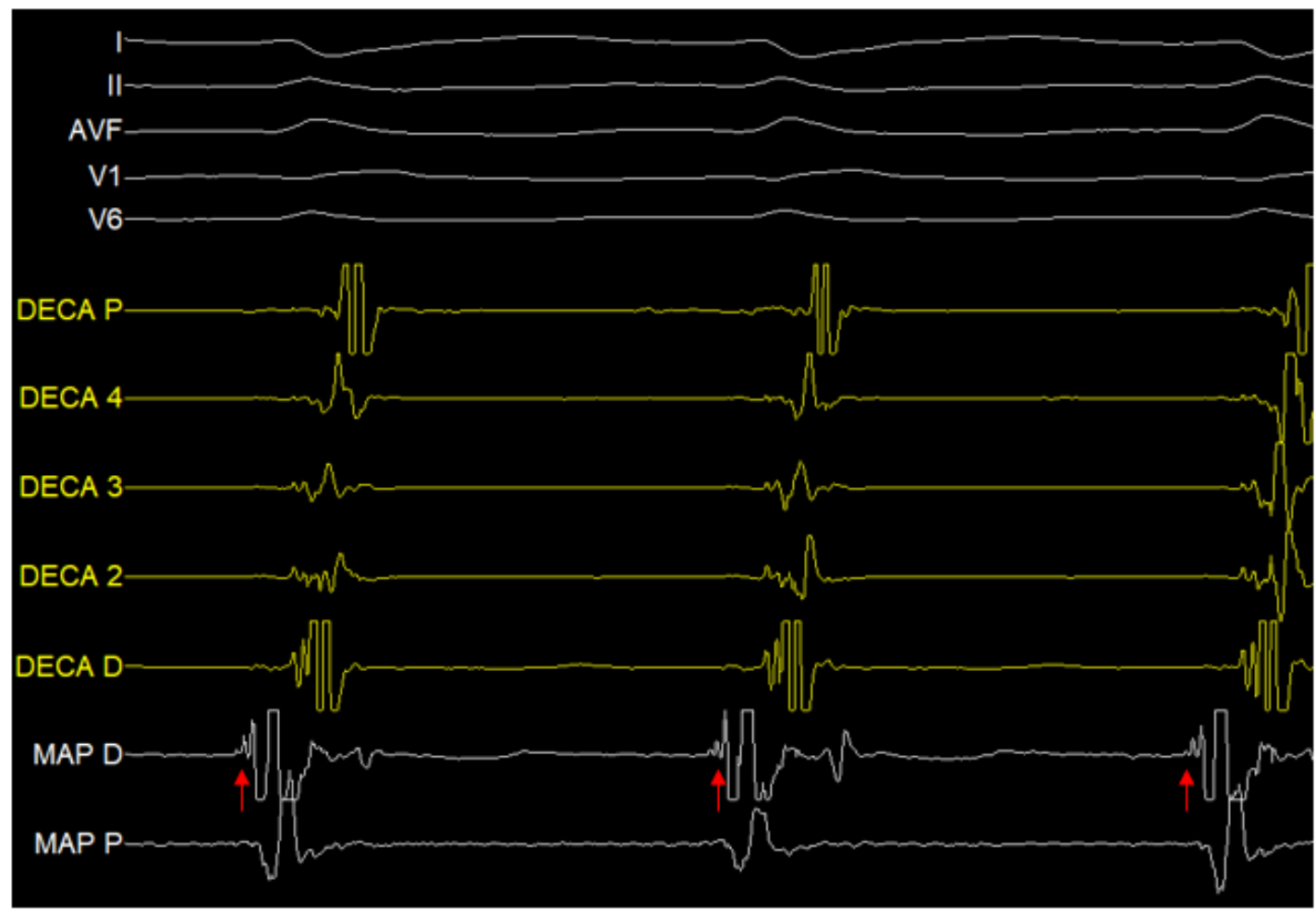

Figure 3. Intracavitary electrogram showing Purkinje potential (red arrow) with 15 ms of precocity. 


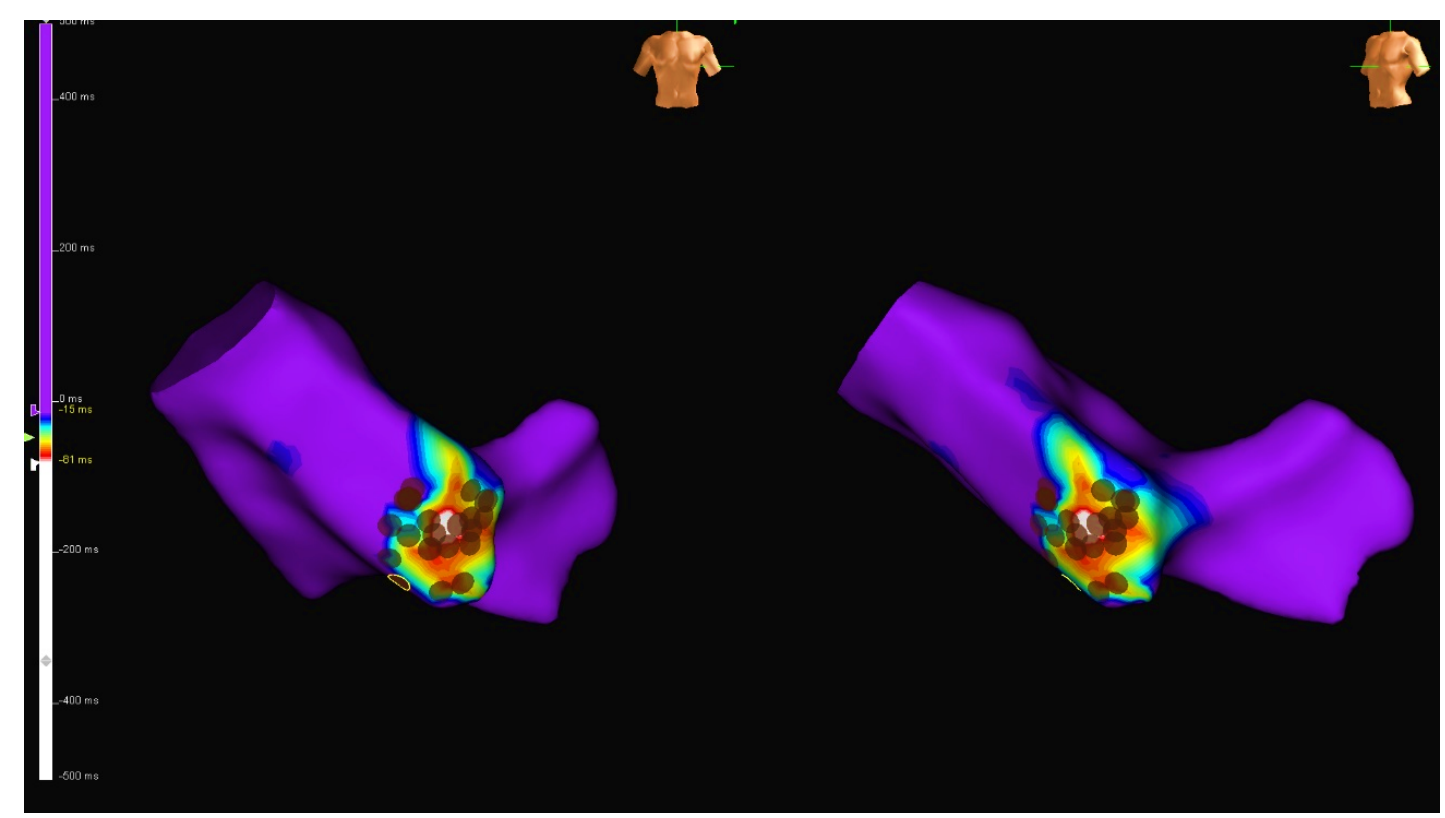

Figure 4. VT activation mapping using EnSite, showing greater precocity of the electrical potential in the white region, where radiofrequency pulses (brown dots) were applied.

\section{DISCUSSION}

Idiopathic VTs correspond to $10 \%$ of the total VTs and are referred to as they occur in a structurally normal heart ${ }^{1,2}$. Those originating in the left anterior fascicle are responsible for $10 \%$ of idiopathic fascicular VTs and occur in a greater proportion (> 60\%) in young males between 15 and 40 years of age $\mathrm{e}^{3,4}$.

Such arrhythmias were initially described by Zipes in 1979, however it was Belhassen who, in 1981, reported a case in which he showed the responsiveness of this arrhythmia to the use of intravenous verapamil. Thus, the entity ended up named after him ${ }^{1-3,5}$. In 1993, Nakagawa raised the hypothesis that Purkinje fibers were part of the origin of the arrhythmia, when identifying a pressystolic potential during VT, obtaining success of the ablation by applying radiofrequency in the earliest location of that potential ${ }^{3,6}$.

The mechanism of these arrhythmias is reentry, in which there is a region of slow conduction, sensitive to verapamil, initiated at the base of the left ventricular septal myocardium, going towards the exit of the left anterior fascicle, corresponding to the orthodromic portion of the circuit. Purkinje fibers complete it, through retrograde conduction ${ }^{1,2,7}$.

The fascicular VT electrocardiogram may eventually be mistaken for paroxysmal supraventricular tachycardia (PSVT) conducted with aberrance ${ }^{2}$. Algorithms for differentiating between VT and PSVT have already been described, however, specifically for fascicular VT, RS $<80 \mathrm{~ms}$ is generally found in all precordial leads and the QRS is relatively narrow (between 110-140 ms). Associated with this, the presence of atrioventricular dissociation and fusion beats considerably increase the sensitivity for the diagnosis of fascicular VT by electrocardiogram analysis ${ }^{5}$.

Depending on the origin, fascicular VTs are classified as: left posterior, with right bundle branch block morphology and axis deviation to the left; left anterior, with right bundle branch block morphology and axis deviation to the right; and septal, with incomplete right bundle branch block morphology and normal axis ${ }^{1,3,8,9}$.

The electrophysiological study certainly defines the type of tachycardia and the location of the circuit. During the tachycardia mapping, two distinct potentials can be found: the Purkinje potential, found 5-25 ms before the QRS and the pre-Purkinje potential, found 30-70 ms before the QRS. The first corresponds to the activation of the fascicle and Purkinje fibers (fast conduction), being a short, high frequency potential. The second corresponds to the activation of the verapamilsensitive septal myocardium (slow conduction) $)^{1,10}$, presenting itself as a low frequency potential ${ }^{10,11}$. 
The prognosis of fascicular VTs, in general, is good ${ }^{2}$, with rare cases of progression to tachycardiomyopathy. Initially, clinical treatment is performed with non-dihydropyridine calcium channel blockers and beta-blockers ${ }^{3,6}$. There are reports of response with the use of sotalol and amiodarone ${ }^{9}$. For patients refractory to medications, there is the option of radiofrequency ablation. The procedure has success rates of up to $95 \%{ }^{12}$, favored with the use of electroanatomical mapping during the procedure.

There are several approaches for mapping and ablation of fascicular VT, especially when the arrhythmia is not sustained during the procedure ${ }^{1,10}$. The use of precocity Purkinje potential during VT as a target is one of the possibilities ${ }^{1,5}$, being the one used in the case described, together with electroanatomical mapping.

\section{AUTHOR'S CONTRIBUTION}

Conceptualization, Silva LTM; Methodology, Silva LTM; Investigation, Silva LTM e Vale PD;Writing - First version, Silva LTM;Writing - Review \& Editing, Margalho CS e Rocha JM; Supervision, Maia HCA.

\section{REFERENCES}

1. Kapa S, Gaba P, DeSimone CV, Asirvatham SJ. Fascicular ventricular arrhythmias: pathophysiologic mechanisms, anatomical constructs, and advances in approaches to management. Circ Arrhythm Electrophysiol. 2017;10(1):e002476. https://doi.org/10.1161/CIRCEP.116.002476

2. Salim SFABS, Jamal SM. Belhassen ventricular tachycardia - a diagnostic challenge in emergency room: case report. Malays J Emerg Med. 2018;3(1).

3. Hoffmayer KS, Gerstenfeld EP. Diagnosis and management of idiopathic ventricular tachycardia. Curr Probl Cardiol. 2013;38(4):13158. https://doi.org/10.1016/j.cpcardiol.2013.02.002

4. Suzuki T, Nakamura Y, Yoshida S, Yoshida Y, Nakamura K, Sasaki T, et al. Radiofrequency catheter ablation of idiopathic left anterior fascicular ventricular tachycardia in children. Heart Rhythm. 2014;11(11):1948-56. https://doi.org/10.1016/j.hrthm.2014.06.024

5. Andrade FR, Eslami M, Elias J, Kinoshita O, Nakazato Y, Marcus Fl, et al. Diagnostic clues from the surface ECG to identify idiopathic (fascicular) ventricular tachycardia: correlation with electrophysiologic findings. J Cardiovasc Electrophysiol. 1996;7(1):2-8. https:// doi.org/10.1111/j.1540-8167.1996.tb00454.x

6. Johnson F, Venugopal K, Khadar SA, Sudhayakumar N, Gupta AK. Idiopathic fascicular ventricular tachycardia. Indian Pacing Electrophysiol J. 2004;4(3):98-103.

7. Ohe T, Shimomura K, Aihara N, Kamakura S, Matsuhisa M, Sato I, et al. Idiopathic sustained left ventricular tachycardia: clinical and electrophysiologic characteristics. Circulation. 1988;77:560-8. https://doi.org/10.1161/01.CIR.77.3.560

8. Ward DE, Nathan AW, Camm AJ. Fascicular tachycardia sensitive to calcium antagonists. Eur Heart J. 1984;5(11):896-905. https://doi. org/10.1093/oxfordjournals.eurheartj.a061589

9. Eynon CA, Howe L, Firoozan S. Fascicular tachycardia: uncommon or just unrecognized? Emerg Med J. 2002;19(5):477-8. https://doi. org/10.1136/emj.19.5.477

10. Ramprakash B, Jaishankar S, Rao HB, Narasimhan C. Catheter ablation of fascicular ventricular tachycardia. Indian Pacing Electrophysiol J. 2008;8(3):193-201.

11. Nogami A. Idiopathic left ventricular tachycardia: assessment and treatment. Card Electrophysiol Rev. 2002;6(4):448-57. https://doi. org/10.1023/A:1021100828459

12. Schreiber D, Kottkamp H. Ablation of idiopathic ventricular tachycardia. Curr Cardiol Rep. 2010;12(5):382-8. https://doi.org/10.1007/ s11886-010-0121-x 